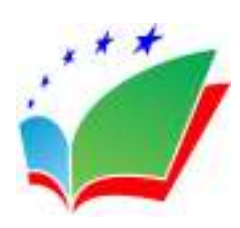

European Journal of Physiotherapy and Rehabilitation Studies

ISSN: 2668-9928

ISSN-L: 2668-9928

Available on-line at: $\underline{\text { www.oapub.org/hlt }}$

\title{
IMMEDIATE EFFECTS OF BACKPACK \\ ON VENTILATION AMONG SCHOOL GOING CHILDREN AGED FROM 7 TO 15 YEARS IN NAVSARI, GUJARAT, INDIA
}

\author{
Hetvi Shukla ${ }^{1}$, \\ Anand Vaghasiya ${ }^{2 i}$, \\ Shirin Shaikh ${ }^{3}$, \\ Khevana Naik ${ }^{4}$ \\ ${ }^{1}$ Dr., MPT,
}

1S. S. Agrawal Institute of Physiotherapy and Medical care Education, Navsari, Gujarat, India ${ }^{2}$ Dr., BPT,

2S. S. Agrawal Institute of Physiotherapy and Medical care Education, Navsari,

Gujarat, India

${ }^{3}$ Dr., BPT,

3S. S. Agrawal Institute of Physiotherapy and Medical care Education, Navsari,

Gujarat, India

${ }^{4}$ Dr., BPT,

${ }^{4}$ S. S. Agrawal Institute of Physiotherapy and Medical care Education, Navsari,

Gujarat, India

\begin{abstract}
:
Background: Backpacks are used popularly by students to carry their school belongings in many countries. Therefore, serious concerns are being raised about the effect of the backpack on children. There is ongoing concern regarding the weight of children's schoolbags and the negative consequences of such heavy loads on the developing spine and cardio-respiratory systems. There are various other factors which are affecting cardiorespiratory fitness in adult as well as children. A significant reduction was reported for most of the ventilatory function parameters while carrying the backpack. Purpose: To check the immediate effect of the backpack on the ventilation of school-going children aged from 7-15 years in Navsari. Method: 210 subjects were taken in this study to check respiratory parameters. All included children were tested in standing position with the head straight after taking written consent from parents. They were further
\end{abstract}

i Correspondence: email anandsvaghasiya@gmail.com 
divided into three age groups ranging from 7-9 years, 10-12 years, and 13-15 years. Spirometry was done using the spirometer of clarity medical Pvt. Ltd. Spirometer used in the study facilitates the total valuation of lung function including forced vital capacity (FVC), forced expiratory volume in one second (FEV1), and peak expiratory flow rate (PEFR). Results: With the help of SPSS software paired sample t-test was done. The parameters of FVC, FEV1, and PEFR showed a significant reduction in the data with a backpack, without a backpack and with one shoulder strap. The result of parameters was $\mathrm{p}<0.005$ except for the value of PEFR with one shoulder strap in the third age group which was $p=0.108$. Conclusion: There is a significant reduction in respiratory function (FVC, FEV1, and PEFR) in correlation with age, weight, and height and bag weight of subjects.

Keywords: age, weight, height, backpack, school going children, forced vital capacity, force expiratory volume in one second, subjects, peak expiratory flow rate

\section{Introduction}

There is ongoing concern regarding the weight of children's schoolbags and the negative consequences of such heavy loads on the developing spine and cardio-respiratory systems. There are various other factors which is affecting cardiorespiratory fitness in adult as well as children. A significant reduction was reported for most of the ventilatory function parameters while carrying the backpack. ${ }^{[3]}$ Musculoskeletal symptoms are believed to be multifactorial and its effect on body systems varies with each and every systems of the body, carriage of heavy schoolbags is a suspected 'contributory factor', and therefore represents an 'overlooked daily physical stress' for school going children with respiratory system more affected which is mentioned by Whittfield et al. ${ }^{[5]}$ Normal respiration is a very Complex mechanism. ${ }^{[6]} \mathrm{It}^{\prime} \mathrm{s}$ function is comprised of mechanical as well as non-mechanical components. Respiration can be affected by various factors, including age, disease, lifestyle, and even change in posture.

The lungs can be extended and compressed in two ways:

1) Downward and upward movement of the diaphragm is responsible for lengthening or shortening of chest cavity.

2) Elevation and depression of the ribs is responsible for increase and decrease in the anteroposterior diameter of the chest cavity. These two methods are shown in figure below.

During inspiration, all respiratory muscle contracts whereas during expiration almost entirely passive process occur which is caused by elastic recoil of the lungs and chest cage. In some conditions, the respiratory muscles normally perform "work" to cause inspiration and not to cause expiration. ${ }^{[6]}$

The work of inspiration can be further divided into three fractions:

1) Compliance work or elastic work - required to expand the lungs against the lung and chest elastic forces. ${ }^{[6]}$ 
2) Tissue resistance work - required to overcome the viscosity of the lung and chest wall structures. ${ }^{[6]}$

3) Airway resistance work - required to overcome airway resistance to movement of air into the lungs. ${ }^{[6]}$

Among the available investigation, pulmonary function test (PFT) is a valuable tool for the assessment of lung function. PFT for lungs can be compared to the ECG for heart. gender and height are the most important predictors of lung function while height linearly correlates with lung size. ${ }^{[8]}$ Adverse effect of this can be seen in ventilatory function which can be harmful in upcoming years. Recently the published studies shows that in Saudi, there was $13.8 \%$ of body weight, which is greater than recommended limit which is $10 \%$ body weight. ${ }^{[18]}$

\section{Methodology}

Study design: Observational Design

Sample size: 210

Sampling method: Convenient Sampling

Study population: School Going children Aged from 7-15, various school of Navsari.

Study duration: from September 2019 to March 2020.

\section{A. Inclusion Criteria}

- school going children aged from 7-15 years;

- primary school children;

- children who can stand;

- children who carry bag to school.

\section{B. Exclusion Criteria}

- subjects who are not able to understand simple commands.

- any other acute or chronic cardio-respiratory disease. ${ }^{[3]}$

- any neurological disease.

- any musculoskeletal disorders including chest and trunk muscles.

- visual or auditory loss as it affects in outcomes. ${ }^{\text {[3] }}$

- upper respiratory tract infections (URTI) like symptoms in past 2 weeks. ${ }^{[24]}$

- h/o any allergy, children with bone deformity of chest or spine. [24]

- family history of atopy, asthma or other chronic lung diseases. [24]

\subsection{Tools and Materials}

- spirometer (hardware and software),

- table,

- computer,

- electronic weighing scale,

- wall mounted height scale,

- cotton, 
- mouthpiece,

- isopropyl (for hygiene- solvent for cleaning mouthpiece),

- pen, pencil, eraser, paper (for data notation).

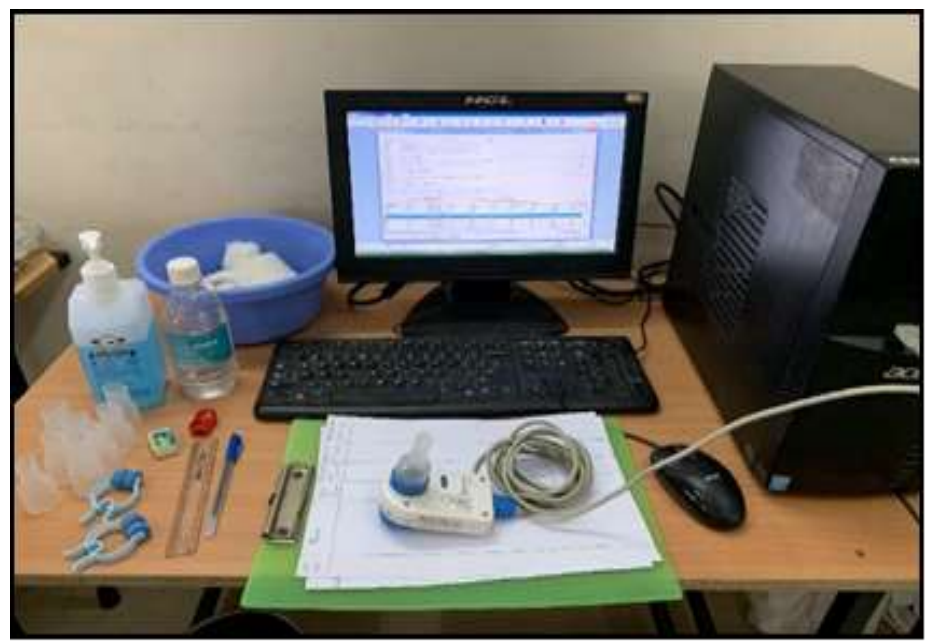

Figure 1: Table setup for data collection

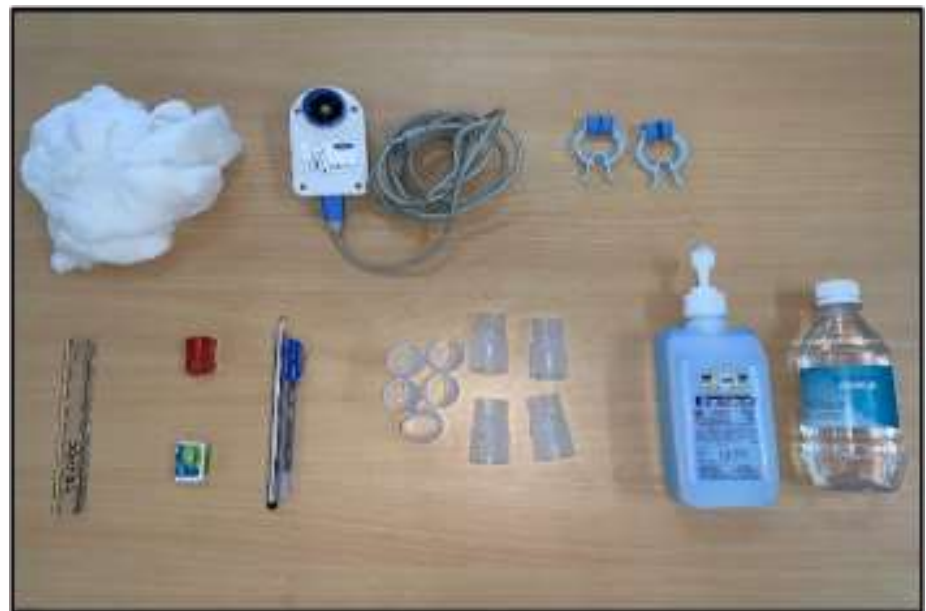

Figure 1: Tools required in procedure: a) cotton b) spirometer c) nose clips d) pen, pencil, eraser d) disposable mouthpiece e) sterillium \& isopropyl

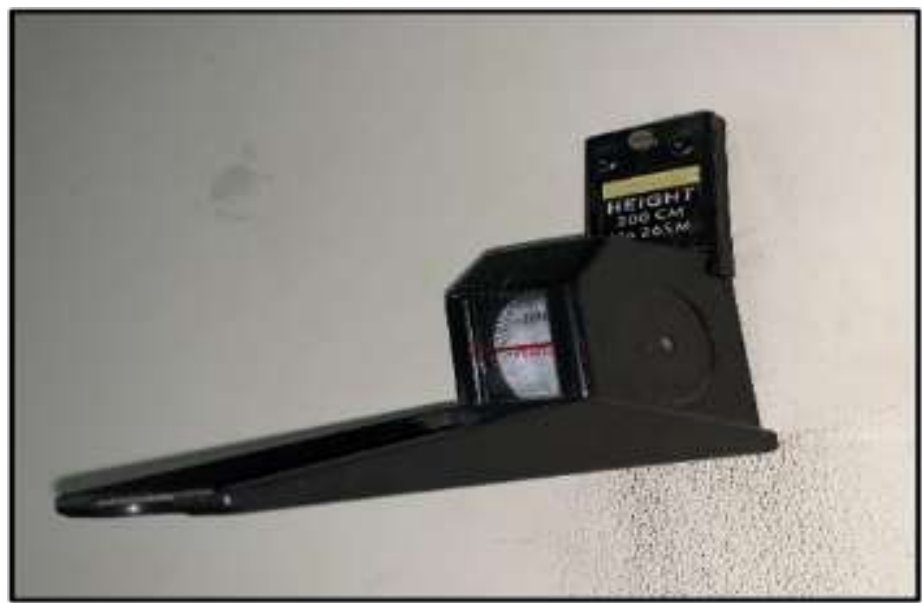

Figure 2: Wall mounted height scale 


\subsection{Procedure}

- After the approval of research guide and coordinator the examiner visited the chosen schools to take the permission of higher authorities, the study aims to check immediate effects of backpacks on respiratory system amongst school going children from age 7-15 years in Navsari.

- The procedure was explained to each principal.

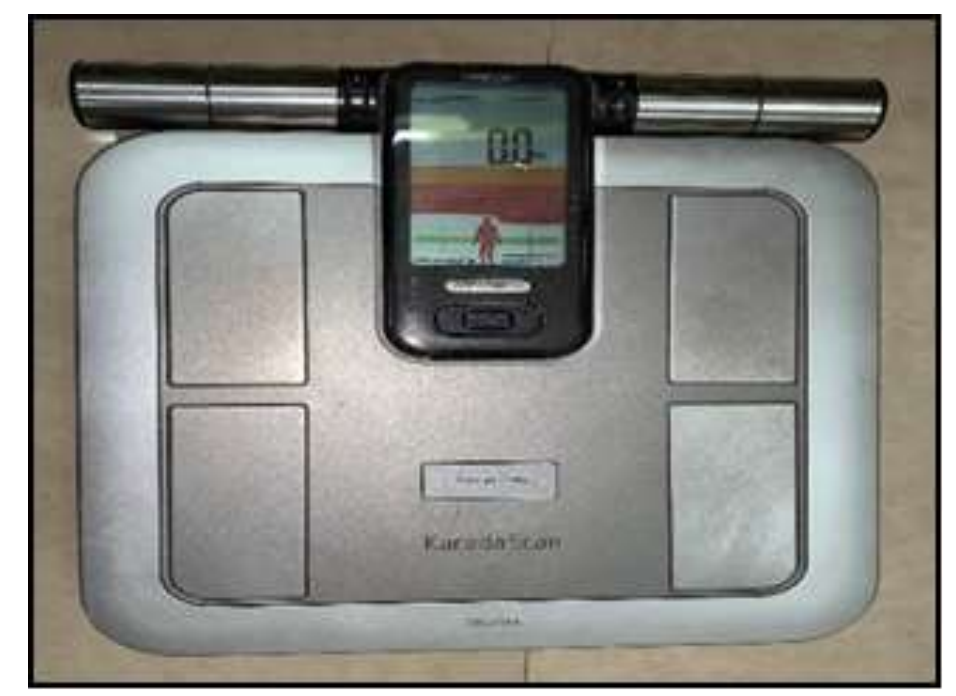

Figure 4: Electronic digital weight scale

- In the same visit the Gujarati consent form were given to the students to take permission of parents.

- At a specified day, the examiner meets the subject and explained them the procedure in simple and understandable manner.

- After the subjects willingly participated, subjects from each class was called individually with their backpack in order to measure the weight of backpack.

- Subjects were taken according to the inclusion criteria of research which is School Going Children aged from 7-15 year, primary school children, children who can stand and children who carry bag to School.

- Screening was done according to the age and standard of subjects.

- First height and weight were measured by the digital weighing scale, it was taken after removing shoes.

- The whole procedure was explained, in standing position the subject first carried out the manure for 30 second without any backpack.

- Subject was explained PFT basic manure about how to put the spirometer mouthpiece in mouth, inhale through nose, take a deep and slow breath in, place your lips around the mouthpiece, exhale fully and with as much as force as possible.

- After 2 minutes again the data was taken with backpack (on shoulder with both straps on).

- Third data was taken after 2 minutes with backpack on one shoulder (single strap). 


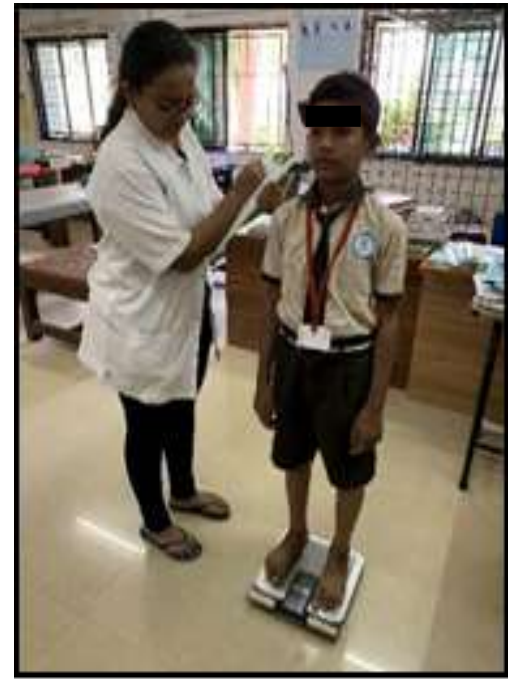

Figure 5: Examiner collecting data of weight

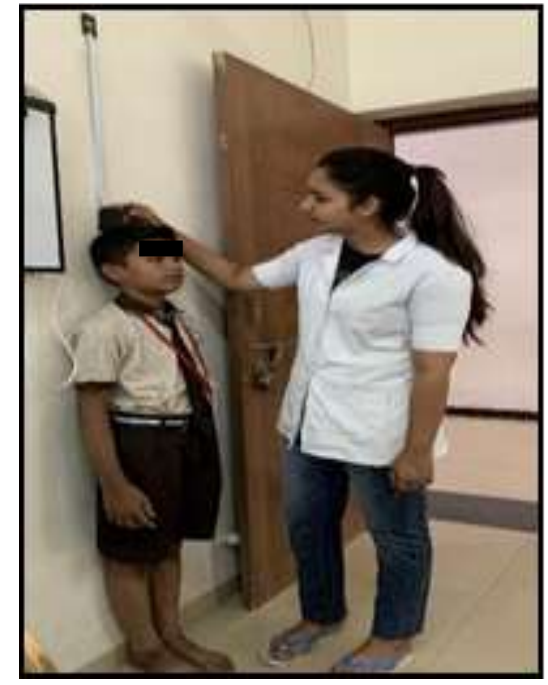

Figure 6: Examiner collecting data of height

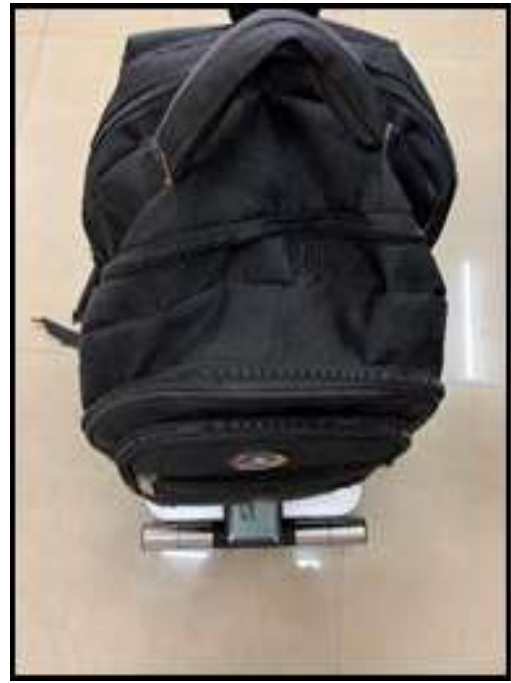

Figure 7: Bag weight measured with weighing scale

- After completion of all successful data the highest value of the 3 trials was noted down.

- The same procedure was repeated in all 210 subjects.

- The mouth piece was cleaned by smearing isopropyl on cotton and cleaning the mouth piece with cotton after every manure to maintain the hygiene.

- After the data was collected it was further taken forward for statistical analysis.

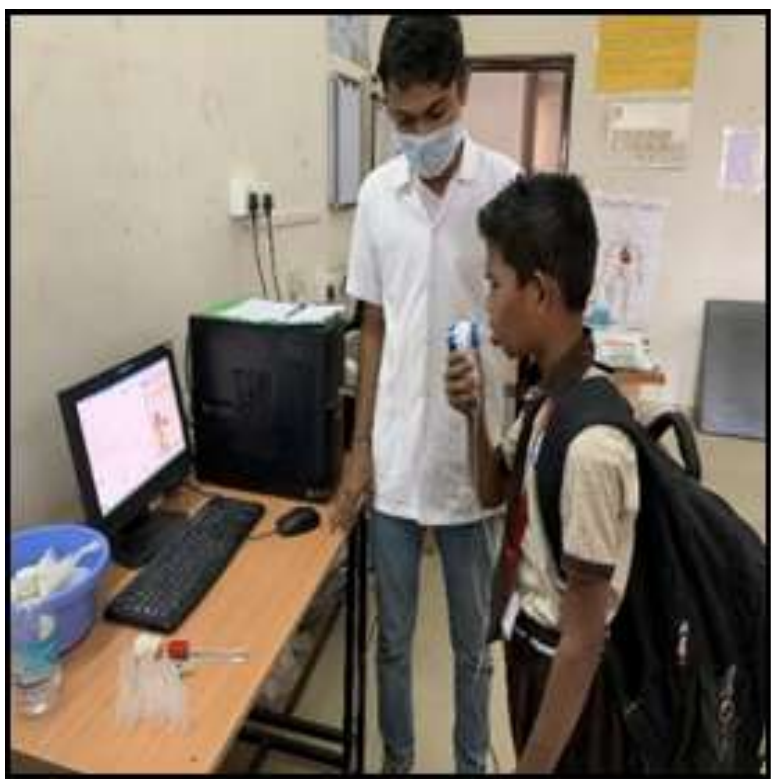

Figure 8: Examiner explaining the procedure of PFT to subject

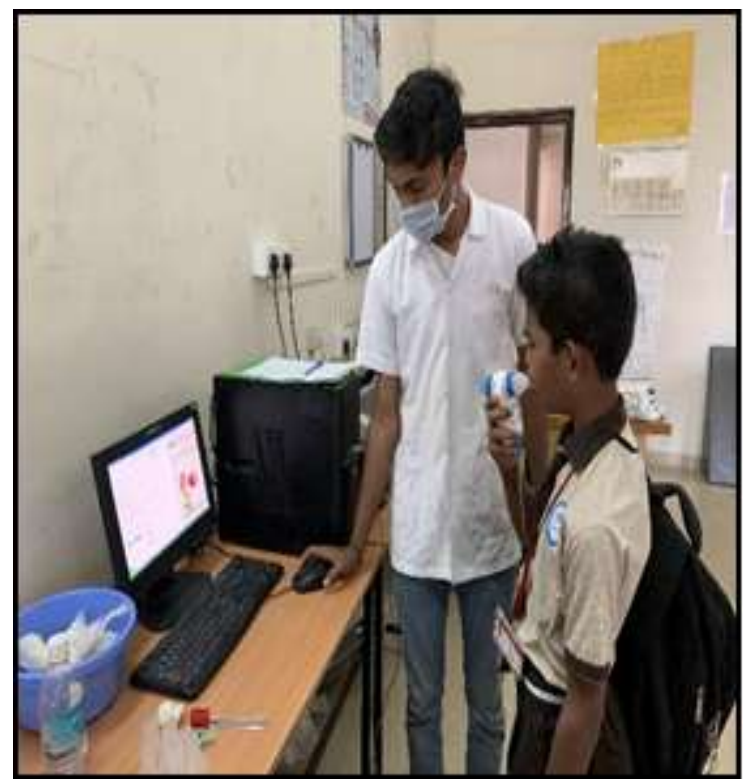

Figure 9: Examiner collecting data of PFT on computer

\subsection{Data and Analysis}

The statistical analysis was done. The subjects were approached by the researcher for data collection of PFT which was later used for effective analysis. Descriptive statistics 
including mean, standard deviation was measured. After analysis of data, paired t-test was used to compare the difference between FVC, FEV1 and PEFR without backpack, FVC, FEV1 and PEFR value with backpack and FVC, FEV1 and PEFR value while carrying backpack on one shoulder for all the subjects and among three age groups. Results were considered to be significant at $\mathrm{p}<0.05$ and confidence interval was set at $95 \%$. All statistical analysis was performed using SPSS version 20.

Table 1: Demographic data

\begin{tabular}{|l|c|c|c|c|c|}
\hline Descriptive Statistics & $\mathbf{N}$ & Minimum & Maximum & Mean & Std. Deviation \\
\hline & 210 & 7 & 15 & 11.24 & 2.159 \\
\hline Age (years) & 210 & 1.07 & 1.78 & 1.4258 & .15634 \\
\hline Height (meter) & 210 & 14.00 & 76.20 & 33.9881 & 13.97914 \\
\hline Weight (kg) & $\mathbf{2 1 0}$ & $\mathbf{2 . 1 0}$ & $\mathbf{1 0 . 8 0}$ & $\mathbf{5 . 4 9 3 3}$ & $\mathbf{1 . 8 4 1 4 0}$ \\
\hline Bag weight (kg) &
\end{tabular}

Table 1 shows the demographic data of age, height, weight, bag weight, FVC, FVC with backpack, FVC with one shoulder strap, FEV1, FEV1 with backpack, FEV1 with one shoulder strap, PEFR, PEFR with backpack and PEFR with one shoulder strap among 210 subjects. The mean age of 210 subjects is 11.24 and SD is 2.159 . The mean characteristic as per height for subjects is 1.425 and SD is 0.156 . For weight the mean is 33.9881 and SD is 13.979 , for bag weight the mean is 5.4933 and SD is 1.8414 .

Table 2: Age group

\begin{tabular}{|l|c|c|}
\hline Group No. & Age (range in year) & Number of students \\
\hline Group 1 & $7-9$ Year & 53 \\
\hline Group 2 & $10-12$ year & 89 \\
\hline Group 3 & $13-15$ year & 68 \\
\hline
\end{tabular}

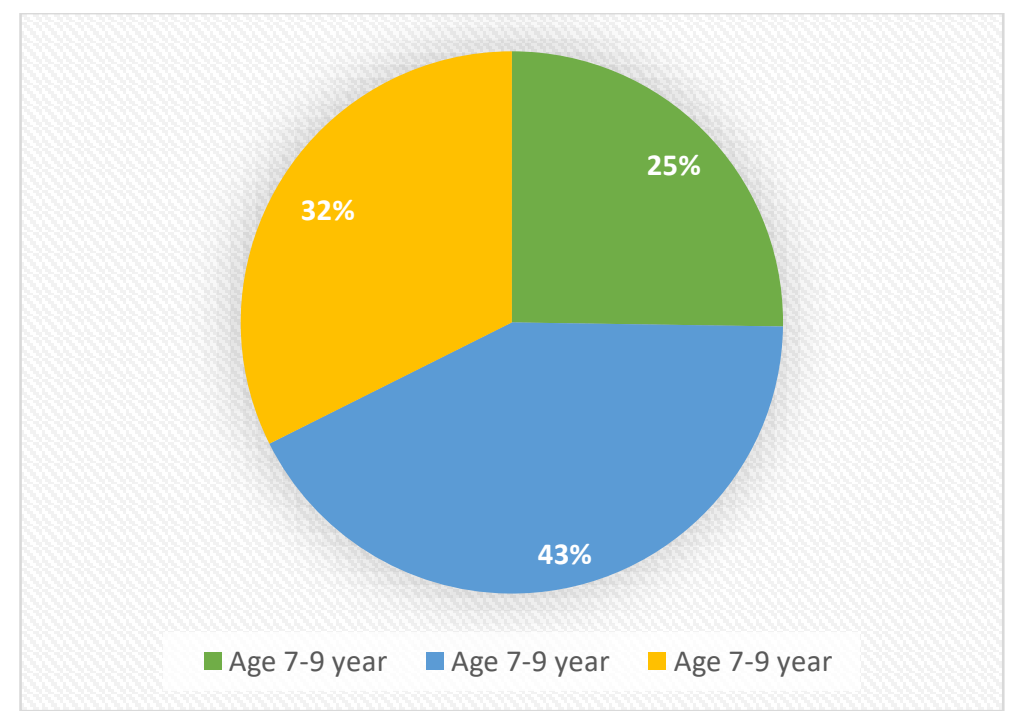

Chart 1: Frequency of Age 
Table 2 and Chart 1 pie chart demonstrates the range of age and the number of students included in it. Group 1 demonstrate the Age range 7-9 years and it consist of 53 students, Group 2 demonstrate the Age range 10-12 years and it consist of 89 students and Group 3 shows Age range 13-15 years and it consist of 68 students.

Table 3: Comparison of values of FVC, Fev1 And PEFR with three different condition

\begin{tabular}{|c|l|c|c|c|c|}
\hline Serial Number & Variables & Mean & SD & t-value & P value \\
\hline 1. & FVC- FVC with Bag & 0.5129 & 0.41105 & 18.06 & 0.000 \\
\hline 2. & FVC- FVC with one strap & 0.27267 & 0.3291 & 12.007 & 0.000 \\
\hline 3. & FEV1- FEV1 with bag & 0.44876 & 0.37085 & 17.536 & 0.00 \\
\hline 4. & FEV1- FEV1 with one strap & 0.25243 & 0.31149 & 11.743 & 0.00 \\
\hline 5. & PEFR- PEFR with bag & 0.77086 & 0.96122 & 11.621 & 0.00 \\
\hline 6. & PEFR- PEFR with one strap & 0.42171 & 1.09856 & 5.563 & 0.00 \\
\hline
\end{tabular}

Confidence interval is $95 \%$ and $p$ value is $<0.05$.

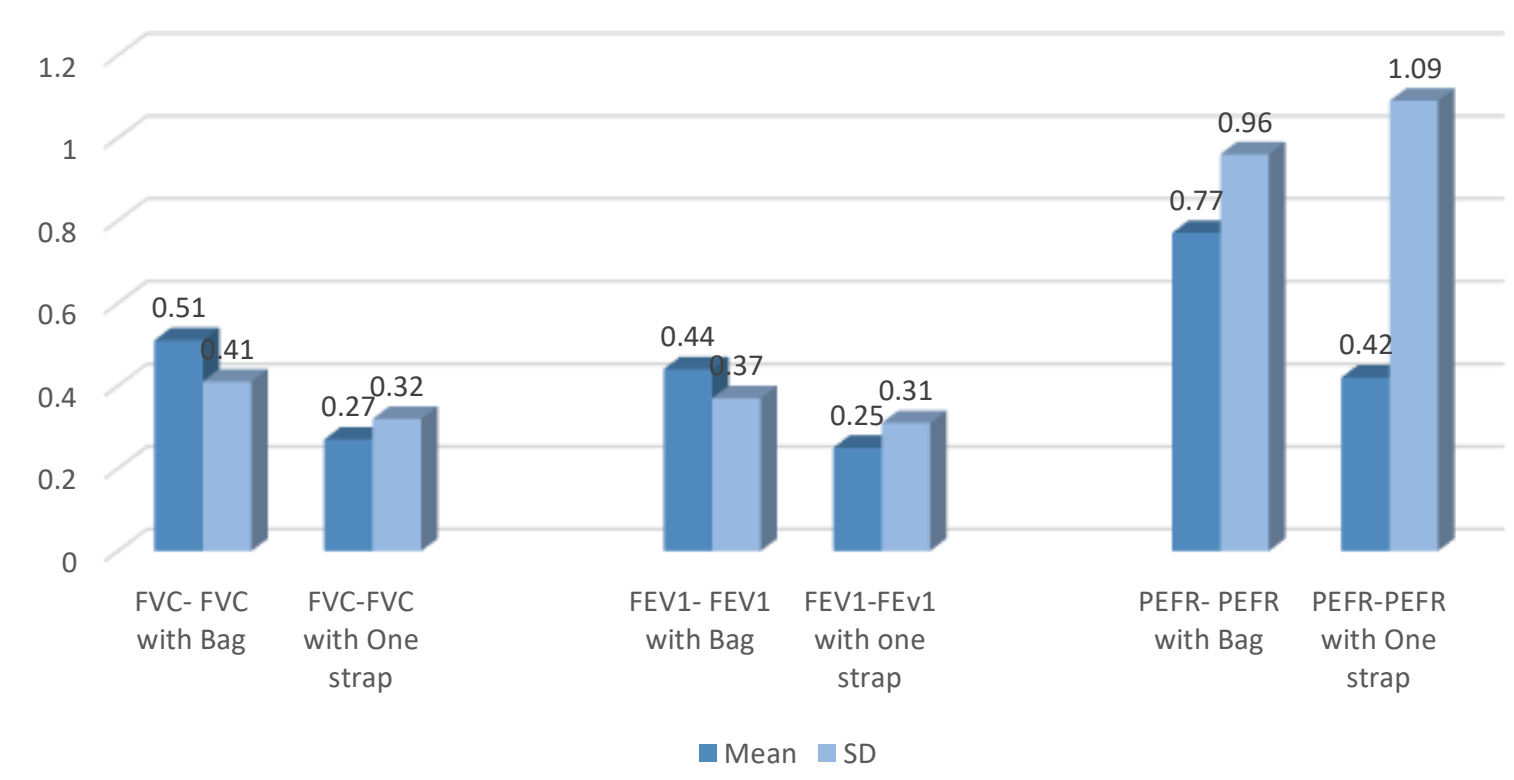

Chart 2: Comparison of values of FVC, FEV1 and PEFR with three different condition

Table 3 and Chart 2 shows result of analysis done by using paired t-test to determine the comparison of values FVC, FEV1 and PEFR with three different condition. The mean for FVC-FVC with backpack is 0.5129 , SD is 0.41105 and $t$-value is 18.06 . The mean for FVCFVC with one strap is $0.27267, \mathrm{SD}$ is 0.3291 and $\mathrm{t}$-value is 12 . 007. The mean for FEV1FEV1 with backpack is $0.44876, \mathrm{SD}$ is 0.37085 and $\mathrm{t}$-value is 17.536 . The mean for FEV1FEV1 with one strap is $0.25243, \mathrm{SD}$ is 0.31149 and $\mathrm{t}$-value is 11.743 . The mean for PEFRPEFR with backpack is $0.77086, \mathrm{SD}$ is 0.96122 and $\mathrm{t}$-value is 11.621 . The mean for PEFRPEFR with one strap is $0.42171, \mathrm{SD}$ is 1.09856 and $\mathrm{t}$-value is 5.563 . The $\mathrm{p}$ value for all the above-mentioned data is $\mathrm{p}<0.05$. 
Hetvi Shukla, Anand Vaghasiya, Shirin Shaikh, Khevana Naik

IMMEDIATE EFFECTS OF BACKPACK ON VENTILATION AMONG SCHOOL

GOING CHILDREN AGED FROM 7 TO 15 YEARS IN NAVSARI, GUJARAT, INDIA

Table 4: Comparison among the age group (FVC)

Paired sample $t$ test among three age group

\begin{tabular}{|c|l|c|c|c|c|}
\hline Age group & Variables & Mean & SD & T & P \\
\hline \multirow{2}{*}{1} & FVC-FVC with Bag & 0.466 & 0.367 & 9.233 & 0.000 \\
\cline { 2 - 6 } & FVC- FVC with one strap & 0.238 & 0.292 & 5.94 & 0.000 \\
\hline \multirow{2}{*}{2} & FVC-FVC with Bag & 0.504 & 0.440 & 10.81 & 0.000 \\
\cline { 2 - 6 } & FVC- FVC with one strap & 0.275 & 0.359 & 7.21 & 0.000 \\
\hline \multirow{2}{*}{3} & FVC-FVC with Bag & 0.557 & 0.404 & 11.37 & 0.000 \\
\cline { 2 - 6 } & FVC- FVC with one strap & 0.295 & 0.315 & 7.71 & 0.000 \\
\hline
\end{tabular}

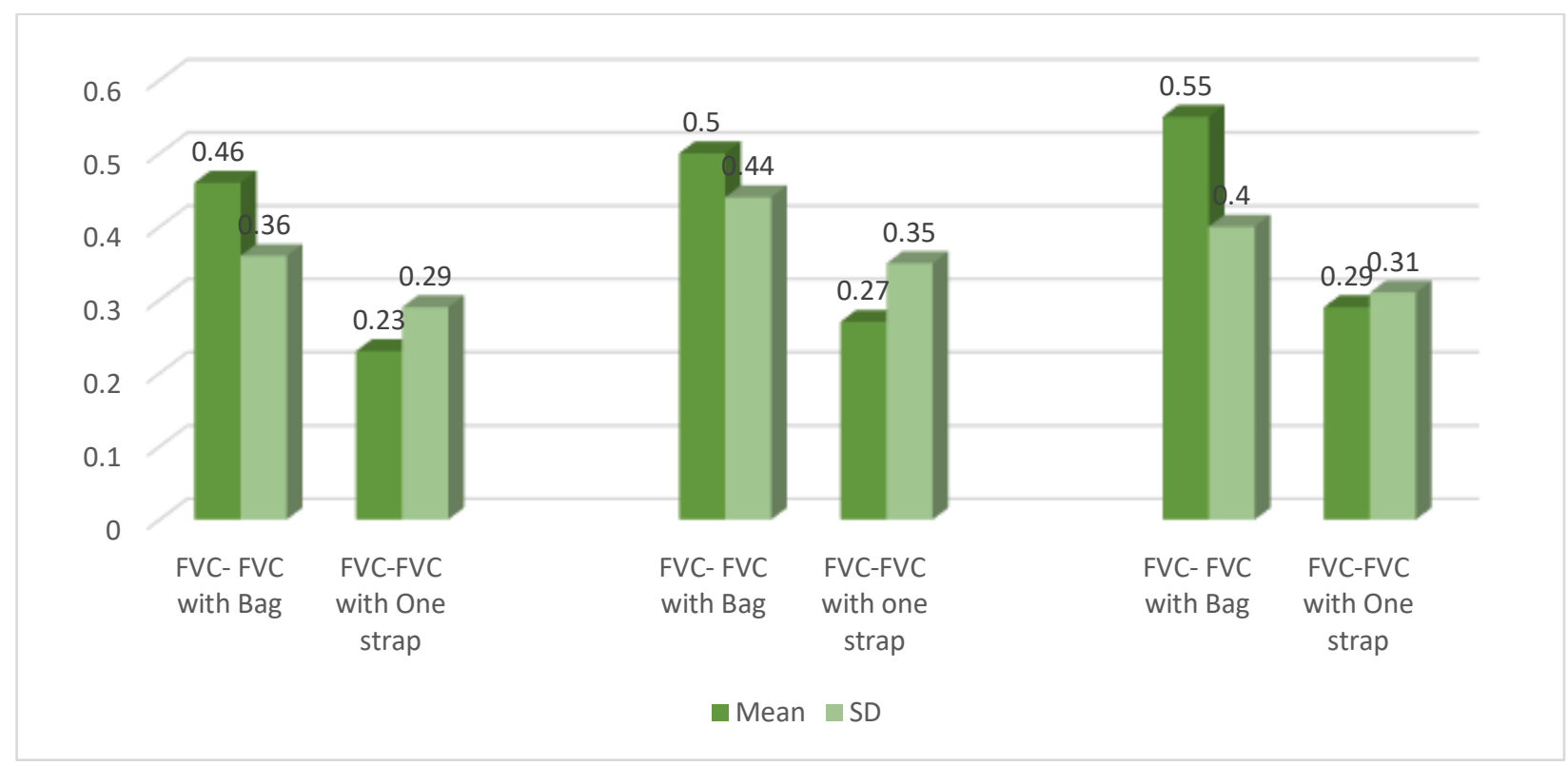

Chart 3: Comparison among the Age group (FVC)

Table 4 and Chart 3 illustrates the comparison of FVC among the three Age groups. For group 1 the mean for FVC-FVC with backpack is 0.466 , SD is 0.367 and $\mathrm{t}$ value is 9.233 and the mean for FVC-FVC with one shoulder strap is 0.238 , SD is 0.292 and $t$-value is 5.94. For group 2 the mean for FVC-FVC with backpack is 0.504 , SD is 0.440 and t-value is 10.81 and the mean for FVC-FVC with one shoulder strap is 0.275 , SD is 0.359 and $t$-value is 7.21. For group 3 the mean for FVC-FVC with bag is 0.557, SD is 0.404 and $t$-value is 11.37 and the mean for FVC-FVC with one shoulder strap is 0.295 , SD is 0.315 and $t$-value is 7.71. The $p$ value for all the three group is $p<0.05$.

Table 5: Comparison among the Age Group (Fev1)

\begin{tabular}{|c|l|c|c|c|c|}
\hline Age group & Variables & Mean & SD & T & P \\
\hline \multirow{2}{*}{1} & FEV1- FEV1 with Bag & 0.44075 & 0.44146 & 7.268 & 0.000 \\
\cline { 2 - 6 } & FEV1- FEV1 with one strap & 0.25057 & 0.35542 & 5.132 & 0.000 \\
\hline \multirow{2}{*}{2} & FEV1- FEV1 with Bag & 0.49281 & 0.37191 & 12.501 & 0.000 \\
\cline { 2 - 6 } & FEV1- FEV1 with one strap & 0.29416 & 0.33251 & 8.346 & 0.000 \\
\hline \multirow{2}{*}{3} & FEV1- FEV1 with Bag & 0.39735 & 0.30130 & 10.875 & 0.000 \\
\cline { 2 - 6 } & FEV1- FEV1 with one strap & 0.19926 & 0.23286 & 7.056 & 0.000 \\
\hline
\end{tabular}




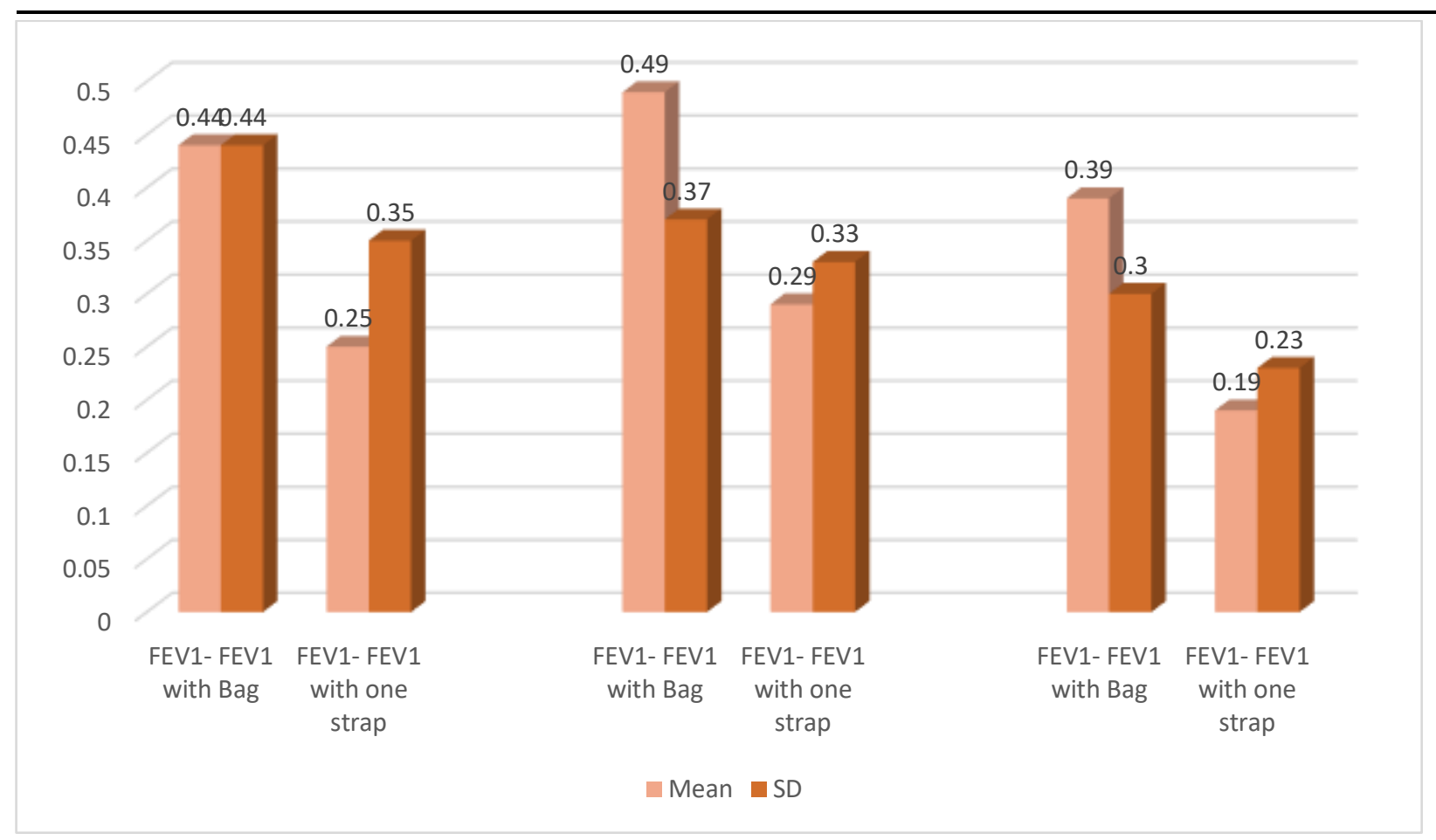

Chart 3: Comparison among the Age Group (FEV1)

Table 5 and Chart 4 shows the comparison of FEV1 among the three Age groups. For group 1 the mean for FEV1-FEV1 with backpack is 0.44075 , SD is 0.44146 and $t$-value is 7.268 and FEV1-FEV1 with one shoulder strap the mean is 0.25057, SD is 0.35542 and $t-$ value is 5.132. For group 2 the mean for FEV1-FEV1 with backpack is 0.49281 , SD is 0.37191 and $t$-value is 12.501 and the mean for FEV1-FEV1 with one shoulder strap is 0.29416 , SD is 0.33251 and $t$-value is 8.346 . For group 3 the mean for FEV1-FEV1 with backpack is $0.39735, \mathrm{SD}$ is 0.30130 and $\mathrm{t}$-value is 10.875 and the mean for FEV1-FEV1 with one shoulder strap is $0.19926, \mathrm{SD}$ is 0.23286 and $\mathrm{t}$-value is 7.065 . The $\mathrm{p}$ value for all the above data is $\mathrm{p}<0.05$.

Table 6: Comparison among the group (PEFR)

\begin{tabular}{|c|l|c|c|c|c|}
\hline Age group & Variables & Mean & SD & T & P \\
\hline \multirow{2}{*}{1} & PEFR- PEFR with Bag & 0.91906 & 0.95643 & 6.996 & 0.00 \\
\cline { 2 - 6 } & PEFR- PEFR with one strap & 0.54755 & 0.8266 & 4.822 & 0.000 \\
\hline \multirow{2}{*}{2} & PEFR- PEFR with Bag & 0.88831 & 1.13849 & 7.361 & 0.000 \\
\cline { 2 - 6 } & PEFR- PEFR with one strap & 0.53157 & 1.32822 & 3.776 & 0.000 \\
\hline \multirow{2}{*}{3} & PEFR- PEFR with Bag & 0.50162 & 0.60042 & 6.889 & 0.000 \\
\cline { 2 - 6 } & PEFR- PEFR with one strap & 0.17985 & 0.91064 & 1.629 & 0.108 \\
\hline
\end{tabular}




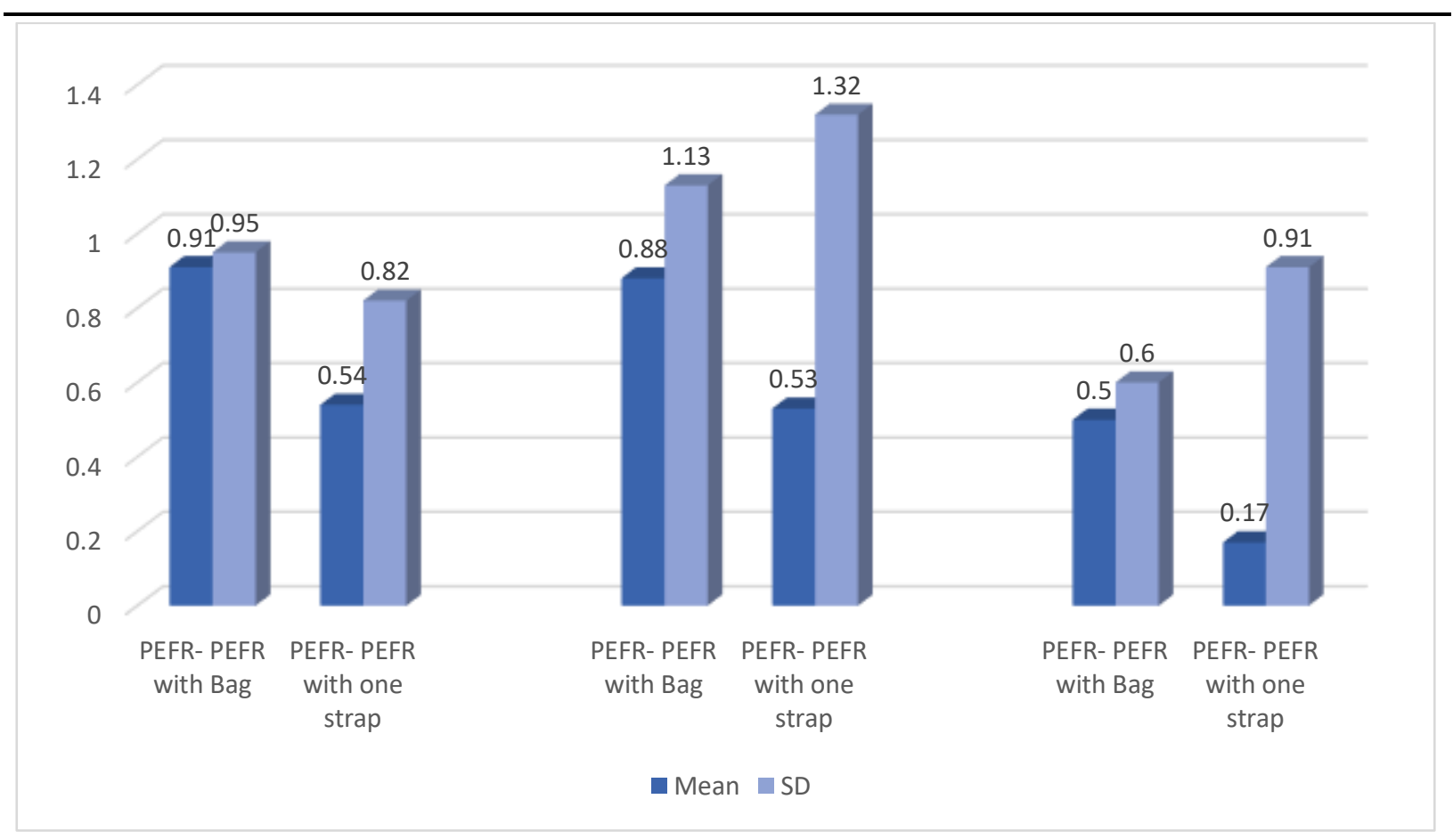

Chart 4: Comparison among the group (PEFR)

Table 6 and Chart 5 shows the comparison of PEFR among the three age groups. For group 1 the mean for PEFR-PEFR with backpack is $0.91906, \mathrm{SD}$ is 0.95643 , $\mathrm{t}$-value is 6.996 and $\mathrm{p}$ value is 0.000 and the mean for PEFR-PEFR with one shoulder strap is $0.54755, \mathrm{SD}$ is $0.8266, \mathrm{t}$-value is 4.822 and $\mathrm{p}$ value is 0.000 . For group 2 the mean for PEFRPEFR with backpack is $0.88831, \mathrm{SD}$ is 1.13849 , $\mathrm{t}$-value is 7.361 and $\mathrm{p}$ value is 0.000 and the mean for PEFR-PEFR with one shoulder strap is $0.53157, \mathrm{SD}$ is $1.32822, \mathrm{t}$-value is 3.776 and $\mathrm{p}$ value is 0.000 . For group 3 the mean for PEFR-PEFR with backpack is 0.50162 , SD is 0.60042 , $\mathrm{t}$-value is 6.889and $\mathrm{p}$ value is 0.000 and the mean for PEFR-PEFR with one shoulder strap is $0.17985, \mathrm{SD}$ is 0.91064 , $\mathrm{t}$-value is 1.629 and $\mathrm{p}$ value is 0.108 .

\section{Discussion}

Respiratory functions are most vital in the entire human body. Understanding the relationship between respiratory mechanism and how it reacts to the stress coming from postural deviation is the key to the exclusive. The aim of the study is to check immediate effect of backpack on Ventilation amongst school going children aged from 7-15 years in Navsari. It was conducted in various schools of Navsari region. Total 210 subjects willingly participated in this research. It cannot be denied that there are no changes in Ventilation amongst subjects. During the research, demonstration of manoeuvre was given to the subject and after that the procedure was started. The study was done on 210 subjects with mean age 11.24 \pm 2.159 ranging from 7-15 years, the outcome measure was determined by PFT which consist of FVC, FEV1 and PEFR components. In previous study, Abeer E. Al-Katheri has conducted study on the impact of backpack load on ventilatory function among $9-12$ year old Saudi girls having mean $10.5 \pm 0.8$. He concluded 
a significant reduction for most of the ventilatory function parameters while carrying the backpack. Similar changes were found in parameters of our research. The present study was carried out with the concept of strong correlation between effect of backpack weight and Ventilation amongst 210 subjects who were divided into three group according to their age. For group 1 the age range was 7-9 years, for group 2 age range was 10-12 years and for group 3 age range was 13-15 years, to investigate the Ventilation including FVC, FEV1 and PEFR. In present study the data found for FVC, FEV1 and PEFR was $\mathrm{p}<0.005$ which shows positive correlation with age, height, weight. It can be summarised from above discussion that there was a significant reduction in most of the parameters after using backpack. These findings are in agreement with the findings of Abeer E. Al Katheri who found that there is reduction in most of the ventilatory function without and with carrying a backpack.

The important aspect of this study is to focus on the effect of backpack on Ventilation of children and how it can affect their musculoskeletal system and breathing mechanism. Our study showed reduction in parameters which shows future complications for the children.

\section{Conclusion}

The result of the present study on 210 subjects have rejected the null hypothesis. Hence it is concluded that there is a significant reduction in the Ventilation parameter which is FVC, FEV1 and PEFR without backpack, with backpack and with one shoulder strap. Further the subjects were divided into three groups. Group 1 (7-9 years), Group 2 (10-12 years) and Group 3(13-15 years). All the same parameters were measured in this three group and it also rejected the null hypothesis which indicates that there is significant reduction in Ventilatory parameters.

\subsection{Limitation of the Study}

1) The duration of study was short.

2) Environmental and personal factors are not so stringent.

3) The understanding of the manoeuvre can be perceived differently by each individual.

\subsection{Future Recommendation}

1) The study was done on a small sample size, so to generalize the effect of the intervention large sample size is needed.

2) The study should have a follow up in order to evaluate the effectiveness that is maintained or not and for what period of time.

3) Future study can be done for correlation between BMI and Ventilation with backpack. 


\section{References}

1. Jaypee Brothers (Jaypeedigital) (2012). Essentials of Medical Physiology. (Jaypee eBooks.) Jaypee Brothers Medical Publishers (P) Ltd.

2. M. Ramprasad, Jeba Alias, Raghuveer A. Effect of Backpack Weight on Postural Angles in Preadolescent Children. Indian Pediatrics. 2009;47.

3. Ochieng B. M. Factors affecting choice of a healthy lifestyle: implications for nurses. $\mathrm{Br}$ J Community Nurs. 2006;11(2):78-81. doi:10.12968/bjcn.2006.11.2.20445

4. Al-Katheri A. E. Impact of backpack load on ventilatory function among 9-12-yearold Saudi girls. Saudi Med J 2013; 34:1255-61.

5. Whittfield J. K., Legg S. J., Hedderley D. I. The weight and use of schoolbags in New Zealand secondary schools. Ergonomics. 2001;44(9):819-24.

6. John E. Hall P. Guyton and Hall Textbook of Medical Physiology, 2016. Print.

7. Srinivas P. Factors Affecting Peak Expiratory Flow Rate and Derive Predictive Equation in Children of 6-12 Years of Age of Karaikal. Journal of Evolution of Medical and Dental Sciences. 2013;2(6).

8. Vijayasekaran D., Subramanyam L., Balachandran A., Shivbalan S. Spirometry in Clinical Practice. Indian Pediatrics. 2003.

9. Jones, R. L., \& Nzekwu, M.-M. U. (September 01, 2006). The Effects of Body Mass Index on Lung Volumes. Chest, 130, 3, 827-833.

10. Pelosi, P., Croci, M., Ravagnan, I., Tredici, S., Pedoto, A., Lissoni, A., \& Gattinoni, L. (January 01, 1998). The effects of body mass on lung volumes, respiratory mechanics, and gas exchange during general anesthesia. Anesthesia and Analgesia, 87, 3, 654-60.

11. Ruppel, G. (2009). Manual of pulmonary function testing. St. Louis, Mo: Mosby Elsevier.

12. Rachhanaa S. Pawaskar S. S. P., Ruchika Patel, Puneet Kaur Dhaliwal, Anjali V. Wagh. A Cross-Sectional Study to Assess Effects of Schoolbag Weight and Musculoskeletal Health Problems in Primary School Students of Kolhapur National Journal of Community Medicine. 2018;9(12).

13. Dockrell, S., C. Kane and E. O'Keeffe. "Schoolbag weight and the effects of schoolbag carriage on secondary school students." (2006).

14. Sung-Hyoun Cho P., Jung-Ho Lee P., Cheol-Yong Kim P. The Changes of Electromyography in the Upper Trapezius and Supraspinatus of Women College Students According to the Method of Bag-carrying and Weight. J Phys Ther Sci 2013; 25:1129-31.

15. Doctor T. H., Trivedi S. S., Chudasama R. K. Pulmonary function test in healthy school children of 8 to 14 years age in south Gujarat region, India. Lung India. 2010;27(3):1458.

16. Stefano Negrini M., Roberta Carabalona, Dipeng. Backpacks on Schoolchildren's Perceptions of Load, Associations with Back Pain and Factors Determining the Load. SPINE. 2002; 27:187-95.

17. Puckree T., Silal S. P., Lin J. School bag carriage and pain in school children. Disabil Rehabil. 2004;26(1):54-9. 
18. Gurin D., Hudak J., Tomkova S. Influence of Postural Training of Diaphragm on Functional Lung Capacity. Alternative \& Integrative Medicine. 2017;06(04).

19. Wang S., Sun X., Hsia T. C., Lin X., Li M. The effects of body mass index on spirometry tests among adults in Xi'an, China. Medicine (Baltimore). 2017;96(15): e6596.

20. Quanjer P. H., Hall G. L., Stanojevic S., Cole T. J., Stocks J., Global Lungs I. Age- and height-based prediction bias in spirometry reference equations. Eur Respir J. 2012;40(1):190-7.

21. Katz S., Arish N., Rokach A., Zaltzman Y., Marcus E. L. The effect of body position on pulmonary function: a systematic review. BMC Pulm Med. 2018;18(1):159.

22. Umesh G. Lalloo, Margaret R. Becklake, Goldsmith C. M. Effect of standing versus sitting Position on Spirometric Indices in Healthy Subjects. Respiration. 1991; 58:1225.

23. Ganeswara Rao Melam S. B., Adel Alhusaini, Mohammed Abdulrahman Alghamdi MSA, Parmveer Kaushal. Effect of Different Positions on FVC and FEV1 Measurements of Asthmatic Patients. J Phys Ther Sci 2014;26.

24. Jat, K. R. (January 01, 2013). Spirometry in children. Primary Care Respiratory Journal: Journal of the General Practice Airways Group, 22, 2, 221-9.

25. Senent JNS-CECACC. Differences in Pulmonary Function Based on Height Prediction Obtained by Using Alternative Measures Respiration. 2009.

26. Geraldine I. Sheir-Neiss R. W. K., Tariq Rahman, Lisa P. Jacobson, Jennifer A. Pelli, The Association of Backpack Use and Back Pain in Adolescents. 2003;28.

27. S. Ostrowski, Barud W. Factors Influencing Lung Function: Are the Predicted Values for Spirometry Reliable Enough? Journal of Physiology and Pharmacology. 2006. 
Appendix 1

\section{S. S. AGRAWAL INSTITUTE OF PHYSIOTHERAPY AND MEDICAL CARE EDUCATION}

સંમતિ પત્ર

હु.

વિદ્યાર્થી.

Form Number: नाર, તરીકે સંમતિ આપું છું અને નીચે દર્શાવેલ વિગતી અને અભ્યાસમાં સહભાગી થવા સંમતિ પ્રદાન કરું છું. મે નીચે જણાવેલા નિયમો પોતે વાંચેલા/ વંચાવેલા છે અને હું તેનાથી સહમત છું. નીચે જણાવેલ પ્રકિયા એ એસ. એસ. અગ્રવાલ ફીઝઓઓથેરાપી કોલેજના ઇન્ટર્ન દ્વારા કરવામાં આવેલ Research નો ભાગ છે. દફતર નો ભાર ઉઠાવ્યા પેહલા અને ભાર ઉઠાવ્યા બાદ બાળકો ના શ્વાસોચ્છવાસ ની પ્રક્રિયા માં તેમજ ફેફસા ની ક્ષમતા માં કોઈ પણ પ્રકારનો ફેરફાર થાય છે કે નહી તે જોવા માટે એક સાધન માં (PFT - Pulmonary Function Test - by clurity Pvt.Ltd) બાળકે દફતર નું વજન ઉઠાવ્યા વગર અને વજન ઉઠાવ્યા બાદ ફૂક મારવાની રહે છે. જેનું માપન કરવામાં આવશે. આ પ્રક્રિયા માં વધુમાં વધુ ૧૦ મિનિટ નો સમય લાગશે કે જે બાળક ને કોઈ પણ પ્રકારે હાનિર્કા નથી અને માત્ર નિદાન નો ભાગ છે.

(૧) મેં આ સંમતી ફોર્મ વાંચી છે અને સમજી છે અને માહિતી મને પ્રદાન કરવામાં આવેલ છે.

(૨) આ સંમતી પત્ર મને સમજવામાં આવી છે.

(૩) મારા અધિકારો અને જવાબદારીઓ મને તપાસ કરનાર દ્વારા સમજવામાં આવી છે.

(૪) મને આ અભ્યાસ માં ભાગ લેવા સાથે સંકળાયેલા જોખમો અંગે સલાહ આપેલ છે.

(પ) હું એ હકીકત થી પરિચિત છું કે હું કોઈ પણ સમયે કોઈ પણ કારણો આપ્યા વિના આ અભ્યાસ માંથી બહાર જઈ શકું છું અને તે આ હોસ્પિટલ માં મારી ભવિષ્ય માં સારવાર પર અસર કરશે નહિ. (૬) હું અહી તપાસર્તર્ત ઓ ને પરવાનગી આપુ છું કે તેઓ આ અભ્યાસ માં ભાગ લેવા પરિણામે જે જાણકારી મેળવી છે તે નિયમનકારી સત્તાવાળાઓ, સરકારી એજન્સીઓ અને નીતિશાસ્ત્ર સમિતિ સામે પ્રકાશિત કરી શકે છે.

(૭) જો મારી માહિતી જાહેર માં રજુ કરવામાં આવે તો મારી ઓળખ ગુમ્ત રાખવામાં આવશે.

આ સમંતી પત્ર સાઈન કરીને, હું પ્રમાણિત કરું છું કે આ પત્ર માં આપેલ માહિતી મને સ્પષ્ટ કરવામાં આવેલ છે અને મને સમજ પડી છે.

વાલી નુ નામ અને સહી:

\begin{tabular}{lll}
\hline विद्यार्थी & નુ & નામ:- \\
\hline જન્મ & તારીખ:-
\end{tabular}

Бंમર: ધોરણ: -

शाળ।

નામ:

વાલીનો કોન્ટેક્ટ નંબર: - 
Appendix 2: Assessment Format for Subjects

- Demographic data:
o Name:
○ Age:
- Gender:
$\circ \operatorname{Height}(\mathrm{m})$ :
○ Weight $(\mathrm{kg})$ :
- Standard/division:
- Name of school:

- Cough:

○ Present/ absent:

- Duration:

- Sputum:

- Personal History:

- Diet:

- Sleep:

- Appetite:

- Vitals:

Blood Pressure:

Respiratory rate:

Pulse Rate:

SpO2:

- Any respiratory condition:

- Chest pain:
- Type:
- Duration
- Area:

- History of asthma or any other lung disease:

- Any recent upper respiratory tract infection:

- Any neurological deficit:

- Any musculoskeletal disorder:

- Any deformity:

- Any allergy: 
Hetvi Shukla, Anand Vaghasiya, Shirin Shaikh, Khevana Naik IMMEDIATE EFFECTS OF BACKPACK ON VENTILATION AMONG SCHOOL GOING CHILDREN AGED FROM 7 TO 15 YEARS IN NAVSARI, GUJARAT, INDIA

\section{Data collection sheet no. 1}

\begin{tabular}{|c|c|c|c|c|c|}
\hline Id No. & Name & Age (in year) & Height (in meter) & Weight (in Kg) & Bag weight (in kg) \\
\hline 1. & & & & & \\
\hline 2. & & & & & \\
\hline 3. & & & & & \\
\hline 4. & & & & & \\
\hline 5. & & & & & \\
\hline 6. & & & & & \\
\hline 7. & & & & & \\
\hline 8. & & & & & \\
\hline 9. & & & & & \\
\hline 10. & & & & & \\
\hline 11. & & & & & \\
\hline 12. & & & & & \\
\hline 13. & & & & & \\
\hline 14. & & & & & \\
\hline 15. & & & & & \\
\hline 16. & & & & & \\
\hline 17. & & & & & \\
\hline 18. & & & & & \\
\hline 19. & & & & & \\
\hline
\end{tabular}

Data collection sheet no. 2

\begin{tabular}{|c|l|l|l|l|l|}
\hline Id No. & Name & Class & $\begin{array}{c}\text { FVC without } \\
\text { backpack }\end{array}$ & $\begin{array}{c}\text { FVC with backpack } \\
\text { on both strap }\end{array}$ & $\begin{array}{c}\text { FVC with backpack } \\
\text { on single strap }\end{array}$ \\
\hline 1. & & & & & \\
\hline 2. & & & & & \\
\hline 3. & & & & & \\
\hline 4. & & & & & \\
\hline 5. & & & & & \\
\hline 6. & & & & & \\
\hline 7. & & & & & \\
\hline 8. & & & & & \\
\hline 9. & & & & & \\
\hline 10. & & & & & \\
\hline 11. & & & & & \\
\hline 12. & & & & & \\
\hline 13 & & & & & \\
\hline 14. & & & & & \\
\hline 15. & & & & & \\
\hline 16. & & & & & \\
\hline 17. & & & & & \\
\hline 18. & & & & & \\
\hline 19. & & & & & \\
\hline 20. & & & & & \\
\hline
\end{tabular}


Hetvi Shukla, Anand Vaghasiya, Shirin Shaikh, Khevana Naik IMMEDIATE EFFECTS OF BACKPACK ON VENTILATION AMONG SCHOOL GOING CHILDREN AGED FROM 7 TO 15 YEARS IN NAVSARI, GUJARAT, INDIA

\section{Data collection sheet no. 3}

\begin{tabular}{|c|l|l|l|l|l|}
\hline Id No. & Name & Class & $\begin{array}{c}\text { FEV1 without } \\
\text { backpack }\end{array}$ & $\begin{array}{c}\text { FEV1 with backpack } \\
\text { on both strap }\end{array}$ & $\begin{array}{c}\text { FEV1 with backpack } \\
\text { on single strap }\end{array}$ \\
\hline 1. & & & & & \\
\hline 2. & & & & & \\
\hline 3. & & & & & \\
\hline 4. & & & & & \\
\hline 5. & & & & & \\
\hline 6. & & & & & \\
\hline 7. & & & & & \\
\hline 8. & & & & & \\
\hline 9. & & & & & \\
\hline 10. & & & & & \\
\hline 11. & & & & & \\
\hline 12. & & & & & \\
\hline 13. & & & & & \\
\hline 14. & & & & & \\
\hline 15. & & & & & \\
\hline 16. & & & & & \\
\hline 17. & & & & & \\
\hline 18. & & & & & \\
\hline 19. & & & & & \\
\hline
\end{tabular}

Data collection sheet no. 4

\begin{tabular}{|c|l|l|l|l|l|}
\hline Id No. & Name & Class & $\begin{array}{c}\text { PEFR without } \\
\text { backpack }\end{array}$ & $\begin{array}{c}\text { PEFR with backpack } \\
\text { on both strap }\end{array}$ & $\begin{array}{c}\text { PEFR with backpack } \\
\text { on single strap }\end{array}$ \\
\hline 1. & & & & & \\
\hline 2. & & & & & \\
\hline 3. & & & & & \\
\hline 4. & & & & & \\
\hline 5. & & & & & \\
\hline 6. & & & & & \\
\hline 7. & & & & & \\
\hline 8. & & & & & \\
\hline 9. & & & & & \\
\hline 10. & & & & & \\
\hline 11. & & & & & \\
\hline 12. & & & & & \\
\hline 13. & & & & & \\
\hline 14. & & & & & \\
\hline 15. & & & & & \\
\hline 16. & & & & & \\
\hline 17. & & & & & \\
\hline 18. & & & & & \\
\hline 19. & & & & & \\
\hline
\end{tabular}


Hetvi Shukla, Anand Vaghasiya, Shirin Shaikh, Khevana Naik

IMMEDIATE EFFECTS OF BACKPACK ON VENTILATION AMONG SCHOOL

GOING CHILDREN AGED FROM 7 TO 15 YEARS IN NAVSARI, GUJARAT, INDIA

Creative Commons licensing terms

Author(s) will retain the copyright of their published articles agreeing that a Creative Commons Attribution 4.0 International License (CC BY 4.0) terms will be applied to their work. Under the terms of this license, no permission is required from the author(s) or publisher for members of the community to copy, distribute, transmit or adapt the article content, providing a proper, prominent and unambiguous attribution to the authors in a manner that makes clear that the materials are being reused under permission of a Creative Commons License. Views, opinions and conclusions expressed in this research article are views, opinions and conclusions of the author(s). Open Access Publishing Group and European Journal of Social Sciences Studies shall not be responsible or answerable for any loss, damage or liability caused in relation to/arising out of conflicts of interest, copyright violations and inappropriate or inaccurate use of any kind content related or integrated into the research work. All the published works are meeting the Open Access Publishing requirements and can be freely accessed, shared, modified, distributed and used in educational, commercial and non-commercial purposes under a Creative Commons Attribution 4.0 International License (CC BY 4.0). 